\title{
Development of Hot Metal Dephosphorization with Lime Powder Top Blowing: Part 2. High Blowing Rate
}

\author{
Masaki MIYATA, ${ }^{1) *}$ Teppei TAMURA ${ }^{2)}$ and Yoshihiko HIGUCHI ${ }^{3)}$ \\ 1) Hirohata R \& D Laboratories Technical Research \& Development Bureau, Nippon Steel \& Sumitomo Metal Corporation, 1 \\ Fuji-cho, Hirohata-ku, Himeji, Hyogo, 671-1188 Japan. $\quad$ 2) Steelmaking R \& D Div., Process Research Laboratories, \\ Nippon Steel \& Sumitomo Metal Corporation, 16-1 Sunayama, Kamisu, Ibaraki, 314-0255 Japan. 3$)$ Department of \\ Mechanical Engineering, College of Industrial Technology, 1-27-1 Nishi-koya, Amagasaki, Hyogo, 661-0047 Japan.
}

(Received on June 26, 2017; accepted on August 2, 2017)

\begin{abstract}
Phosphorus in steel is detrimental element for mechanical properties and dephosphorization treatment of hot iron is necessary to produce high-grade steel products. However, it is difficult to perform dephosphorization treatment to attain lower phosphorus content using $\mathrm{CaO}-\mathrm{SiO}_{2}-\mathrm{FeO}$ flux without fluorite of which use is limited owing to stringent environmental regulations. It is because increasing slag basicity is difficult without slagging promotion agent. In the present work, addition of ladle slag and lime powder top blowing method were applied in $2 \mathrm{t}$ test converter to obtain the higher slag basicity. Obtained results are as follows: (1) phosphorus content of hot iron decreased to 0.001 mass \% under the condition of (CaO)/ $\left(\mathrm{SiO}_{2}\right)=3$. (2) Rate constant, $\mathrm{K}$, of dephosphorization reaction below $[\mathrm{P}]=0.02$ mass $\%$ increased with increasing bottom gas flow rate, but $K$ decreased under the condition of too much bottom gas flow rate. (3) Phosphorus distribution in the final stage of blowing was much higher than predicted values on a basis of thermodynamic relation between top slag and hot iron. (4) It is suggested that the $\mathrm{FeO}-\mathrm{CaO}$ melt formed at hot spot is capable of decreasing the phosphorus content of hot iron to the ultralow range even at high temperature at hot spot.
\end{abstract}

KEY WORDS: dephosphorization; $\mathrm{CaO}$ powder; top blowing; hot spot; ladle slag.

\section{Introduction}

Phosphorus in steel is detrimental element for mechanical properties and dephosphorization treatment of hot iron is necessary to produce high-grade steel products. Dephosphorization treatment using $\mathrm{CaO}-\mathrm{SiO}_{2}-\mathrm{FeO}$ flux has been studied by many researchers ${ }^{1-5)}$ and fluorite is found an excellent slagging promotion agent. However, its use is currently limited owing to stringent environmental regulations. As a result, it is difficult to attain a high dephosphorization ratio due to low basicity of slag.

Ban-ya et al. studied alumina, $\mathrm{Al}_{2} \mathrm{O}_{3}$, as a substitute of fluorite and showed that the $\mathrm{CaO}-\mathrm{Al}_{2} \mathrm{O}_{3}-\mathrm{Fe}_{\mathrm{t}} \mathrm{O}$ flux has sufficient dephosphorization capability where $\mathrm{Al}_{2} \mathrm{O}_{3} / \mathrm{CaO}$ is as low as 1/9. ${ }^{6}$ Based on these results, one of the present authors performed hot iron dephosphorization experiments using the $\mathrm{CaO}-\mathrm{SiO}_{2}-\mathrm{FeO}-\mathrm{Al}_{2} \mathrm{O}_{3}$ flux at $2 \mathrm{~kg}$ crucible-type and $2 \mathrm{t}$ converter-type tests and attained a high dephosphorization ratio under the condition that $(\mathrm{CaO}) /\left(\mathrm{SiO}_{2}\right)$ is 1.6-2.0 and $\left(\mathrm{A}_{2} \mathrm{O}_{3}\right)$ is 5-10 mass\%. ${ }^{7,8)}$ However, high dephosphorization ratio was not attained when the basicity of the charged flux was above 2.0 because observed slag basicity did not rise over 2.0 owing to the low temperature of the hot iron below $1673 \mathrm{~K}$.

\footnotetext{
* Corresponding author: E-mail: miyata.8pm.masaki@jp.nssmc.com DOI: http://dx.doi.org/10.2355/isijinternational.ISIJINT-2017-365
}

On the other hand, lime powder top blowing method has been developed in which oxygen gas containing lime powder is blown on a hot iron surface during decarburization at BOF. ${ }^{9,10)}$ The powders at hot spot around $2500 \mathrm{~K}$ easily melt and abruptly decrease the phosphorus content below 0.02 mass $\%$ at the initial stage. In this method, powder is supplied throughout the period of BOF blowing; therefore, the slag basicity is comparatively low at the initial stage. It is thought to be possible to increase slag basicity and decrease phosphorus content to the lower value by both blowing all the powder at the stage of hot iron and using ladle slag as alumina source. However, the powder blowing method has not been applied to hot iron pretreatment and the effect has not been studied. Therefore, in the present paper, top and bottom test converter experiments at a $2 \mathrm{t}$ scale were carried out, and the obtained results were discussed to confirm the performance of powder top blowing method at hot iron pretreatment.

\section{Experiments}

\subsection{Procedure of Experiments}

After the addition of the molten iron of $2 \mathrm{t}$ followed by charging iron ore and ladle slag into the test converter, oxygen gas and lime powder of less than $0.15 \mathrm{~mm}$ of grain-size were blown on the melt surface through the top lance and rinsing time was set afterwards. Composition of 


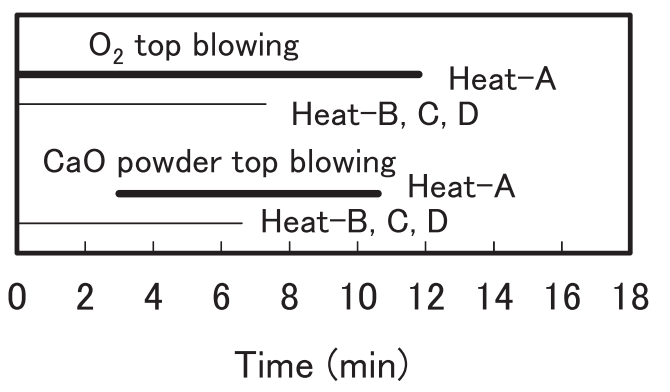

Fig. 1. Time chart of top blowing of oxygen gas and lime powder.

Table 1. Experimental conditions.

\begin{tabular}{ccccc}
\hline Heat & $\begin{array}{c}\mathrm{QB}_{\mathrm{B}} \\
\left(\mathrm{Nm}^{3} \cdot \mathrm{min}^{-1} \cdot \mathrm{t}^{-1}\right)\end{array}$ & $\begin{array}{c}\mathrm{Q}_{\mathrm{T}} \\
\left(\mathrm{Nm}^{3} \cdot \mathrm{min}^{-1} \cdot \mathrm{t}^{-1}\right)\end{array}$ & $\begin{array}{c}\mathrm{Q}_{\mathrm{P}} \\
\left(\mathrm{kg} \cdot \mathrm{min}^{-1} \cdot \mathrm{t}^{-1}\right)\end{array}$ & $\begin{array}{c}\mathrm{t}_{\text {blowing }} \\
(\mathrm{min})\end{array}$ \\
\hline $\mathrm{A}$ & 0.5 & 1.7 & 2.1 & 12.0 \\
$\mathrm{~B}$ & 0.5 & 3.3 & 2.8 & 8.0 \\
$\mathrm{C}$ & 1.0 & 3.3 & 2.8 & 6.5 \\
$\mathrm{D}$ & 1.6 & 3.3 & 2.8 & 6.5 \\
\hline
\end{tabular}

$\mathrm{Q}_{\mathrm{B}}$ : argon bottom blowing rate

$\mathrm{Q}_{\mathrm{T}}$ : oxygen top blowing rate

$\mathrm{Q}_{\mathrm{p}}$ : lime powder top feeding rate

hot iron was $[\mathrm{C}]=4.3$ mass $\%,[\mathrm{Si}]=0.29$ mass $\%,[\mathrm{Mn}]=0.3$ mass $\%$ and $[\mathrm{P}]=0.10$ mass $\%$. Composition of ladle slag was $(\mathrm{CaO}) /\left(\mathrm{SiO}_{2}\right)=5.0,(\mathrm{~T} . \mathrm{Fe})=8$ mass $\%$ and $\left(\mathrm{Al}_{2} \mathrm{O}_{3}\right)=19$ mass\%. Amount of iron ore, ladle slag and lime powder were $10 \mathrm{~kg} \cdot \mathrm{t}^{-1}, 17.3 \mathrm{~kg} \cdot \mathrm{t}^{-1}$ and $17.0 \mathrm{~kg} \cdot \mathrm{t}^{-1}$, respectively. The amount of lime power was determined so as for charged agents of basicity to be 3.0. Lime powder top feeding rate was determined to satisfy the condition for keeping $\mathrm{FeO}-$ $\mathrm{CaO}$ melt formed at hot spot. In Heat-A, lower powder feeding rate was chosen taking into consideration low formation rate of $\mathrm{FeO}$ at hot spot due to lower top oxygen flow rate,

Top oxygen blowing flow rate, $\mathrm{Q}_{\mathrm{T}}$, and bottom blowing flow rate, $\mathrm{Q}_{\mathrm{B}}$, were set to be $1.7-3.3 \mathrm{Nm}^{3} \cdot \mathrm{min}^{-1} \cdot \mathrm{t}^{-1}$ and $0.5-1.6 \mathrm{Nm}^{3} \cdot \mathrm{min}^{-1} \cdot \mathrm{t}^{-1}$, respectively. The timing chart of top blowing is shown in Fig. 1. Temperature was raised to the aimed value of $1673 \mathrm{~K}\left(1400^{\circ} \mathrm{C}\right)$ at the end of blowing. Temperature of hot iron was measured using sub-lance loaded with thermocouple probe during the experiments. The experimental conditions are shown in Table 1.

\section{Results}

\subsection{Change in Temperature of Hot Iron during Treat- ment}

Time variation in temperature of hot iron is shown in Fig. 2. The temperature of each heat reached approximately $1673 \mathrm{~K}$ at the final stage of blowing. Longer blowing time in Heat-A compared with the other heats resulted from the low flow rate of the top blowing oxygen gas.

\subsection{Change in the Contents of Hot Iron during Treat- ment}

Time variation in $[\mathrm{C}]$ of hot iron is shown in Fig. 3. The decarburization rate in Heat-A was lower than those in Heat-B, Heat-C, and Heat-D where the flow rate of the top blowing oxygen gas, $\mathrm{Q}_{\mathrm{T}}$, was higher than in Heat-A.

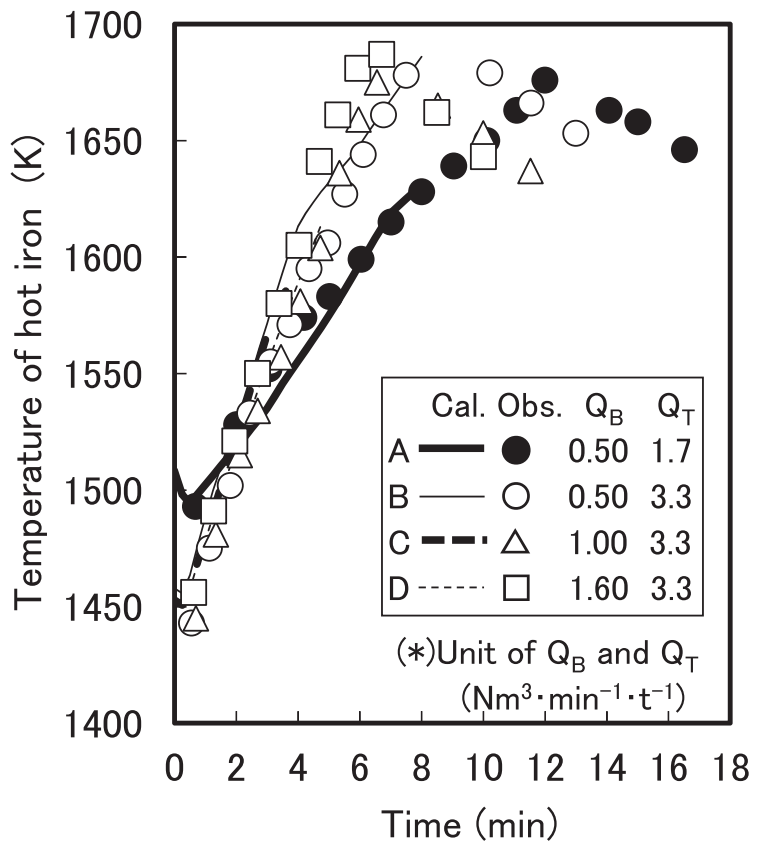

Fig. 2. Time variation in temperature of hot iron.

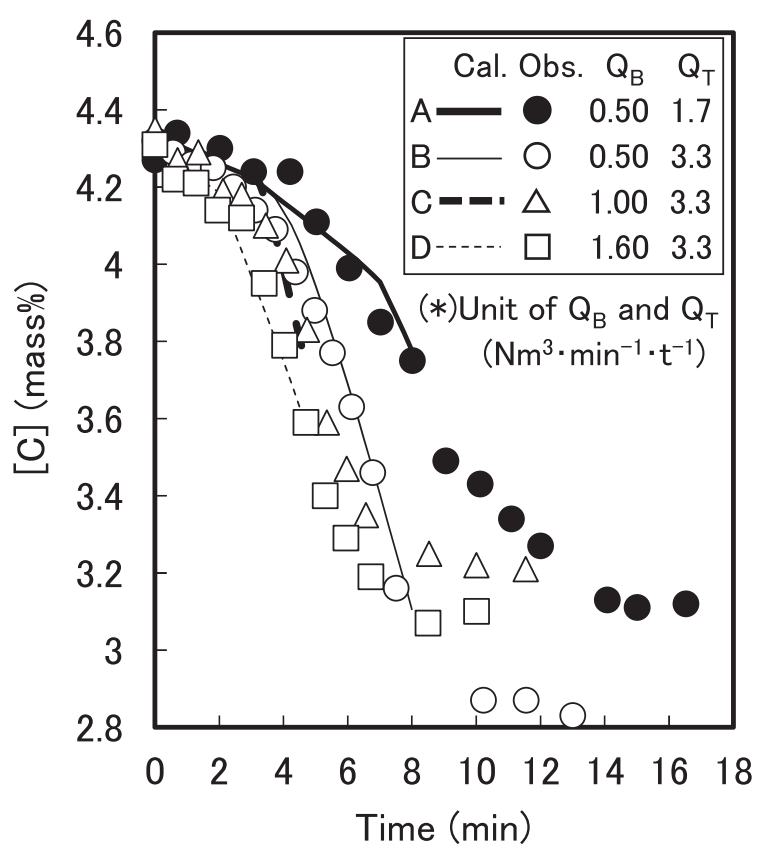

Fig. 3. Time variation in carbon content of hot iron.

The initiation of decarburization became earlier as the flow rate of the bottom blowing argon gas, $\mathrm{Q}_{\mathrm{B}}$, increased. This suggests that the increase in $\mathrm{Q}_{\mathrm{B}}$, facilitates desiliconization and brings forward it.

Time variation in $[\mathrm{P}]$ of hot iron is shown in Fig. 4. Dephosphorization proceeded throughout blowing for 12 min and $[\mathrm{P}]$ decreased below 0.002 mass $\%$ in Heat-A where $\mathrm{Q}_{\mathrm{T}}$ and $\mathrm{Q}_{\mathrm{B}}$ were 1.7 and $0.5 \mathrm{Nm}^{3} \cdot \mathrm{min}^{-1} \cdot \mathrm{t}^{-1}$, respectively. On the other hand, the dephosphorization rate prominently increased with increasing $\mathrm{Q}_{\mathrm{T}}$ and $[\mathrm{P}]$ decreased to 0.001 mass $\%$ within 8 min as shown in Heat-B and Heat-C where $\mathrm{Q}_{\mathrm{T}}$ was twice as much as in Heat-A. Under the same condition for $\mathrm{Q}_{\mathrm{T}}$ of $3.3 \mathrm{Nm}^{3} \cdot \mathrm{min}^{-1} \cdot \mathrm{t}^{-1}$, the dephosphorization rate increased with increasing $\mathrm{Q}_{\mathrm{B}}$. However, $[\mathrm{P}]$ decreased to $0.006 \mathrm{mass} \%$ at $6.5 \mathrm{~min}$ and rephosphorization occurred afterward in Heat-D where $\mathrm{Q}_{в}$ was set to be the highest 


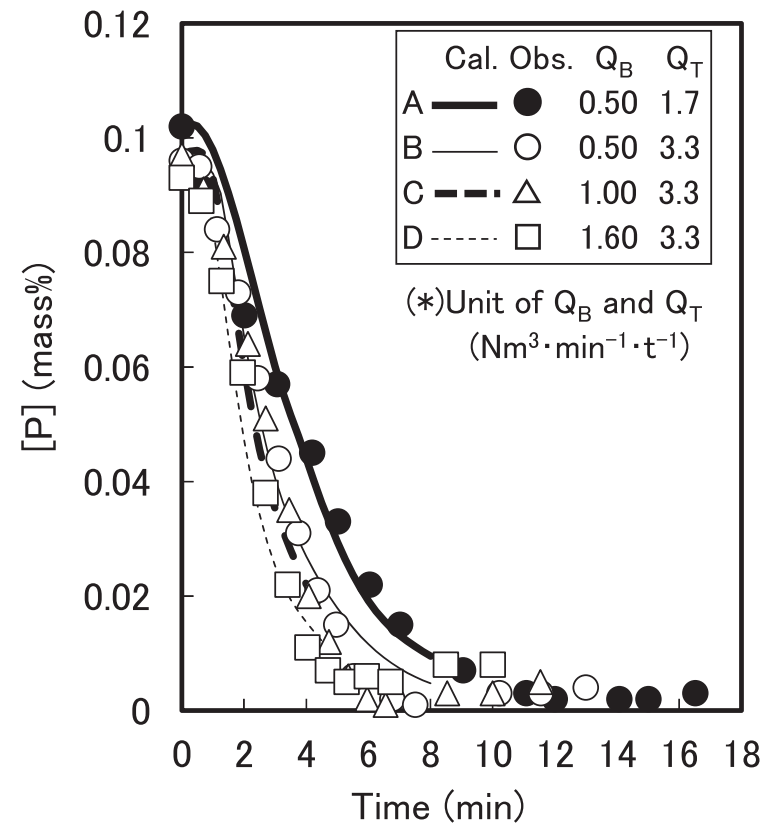

Fig. 4. Time variation in phosphorus content of hot iron.

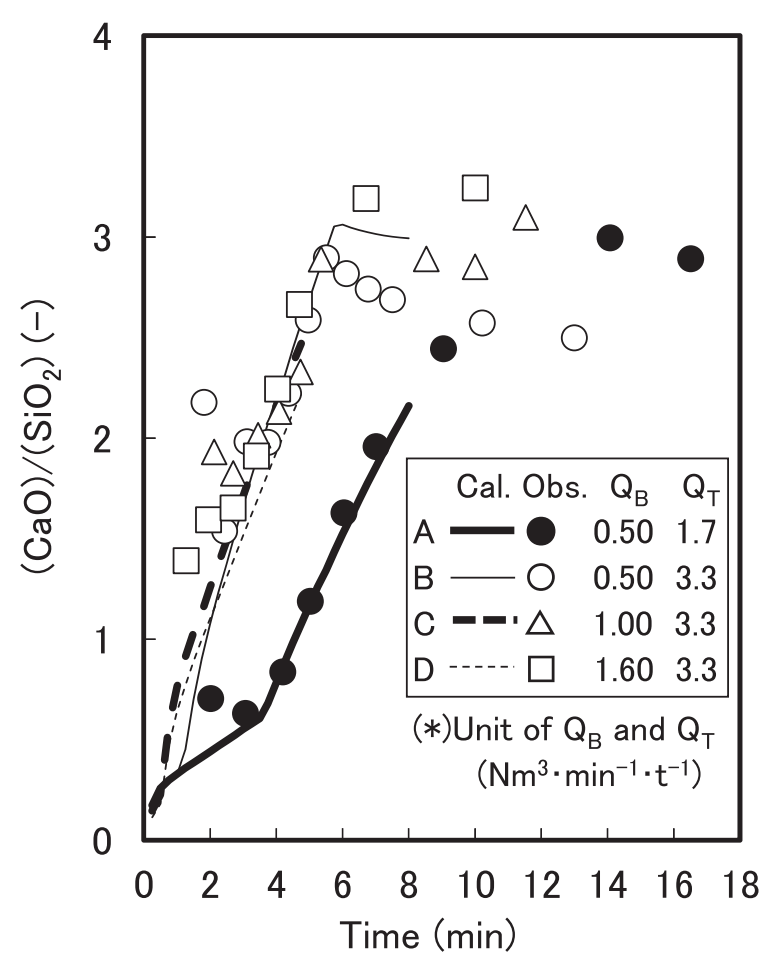

Fig. 5. Time variation in slag basicity, $(\mathrm{CaO}) /\left(\mathrm{SiO}_{2}\right)$.

of all heats. It is suggested that high stirring power due to high bottom gas flow rate in Heat-D led to low $(\mathrm{FeO})$ and rephosphorization in the final stage.

\subsection{Change in the Contents of Slag during Treatment}

Time variation in slag basicity, $(\mathrm{CaO}) /\left(\mathrm{SiO}_{2}\right)$, is shown in Fig. 5. The slag basicity in Heat-A was lower than those in the other heats at the initial stage owing to the lower feeding rate of lime powder. At the final stage of blowing, $(\mathrm{CaO}) /$ $\left(\mathrm{SiO}_{2}\right)$ in all heats reached approximately 3.0, which is equal to the basicity of charged agents. The relation between the charged and observed $(\mathrm{CaO}) /\left(\mathrm{SiO}_{2}\right)$ is shown in Fig. 6. It is suggested that the ladle slag dissolved at the initial stage of

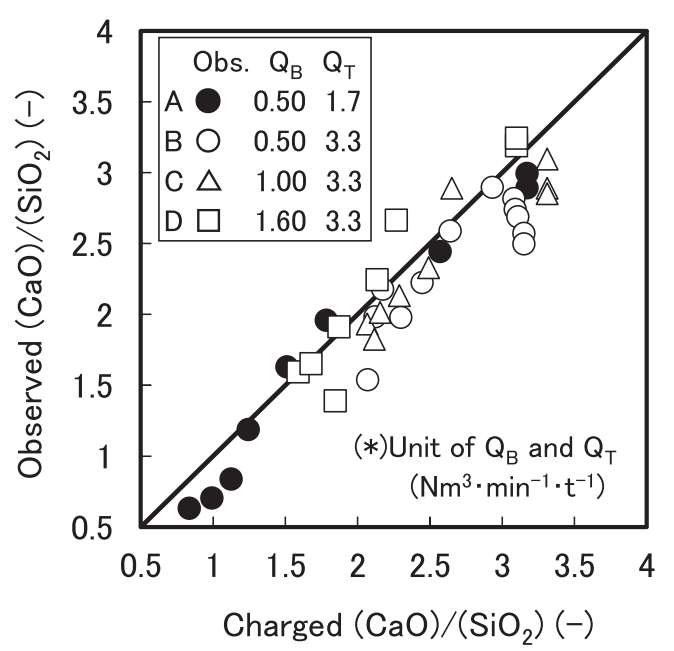

Fig. 6. Relation between charged and observed basicity of slag.

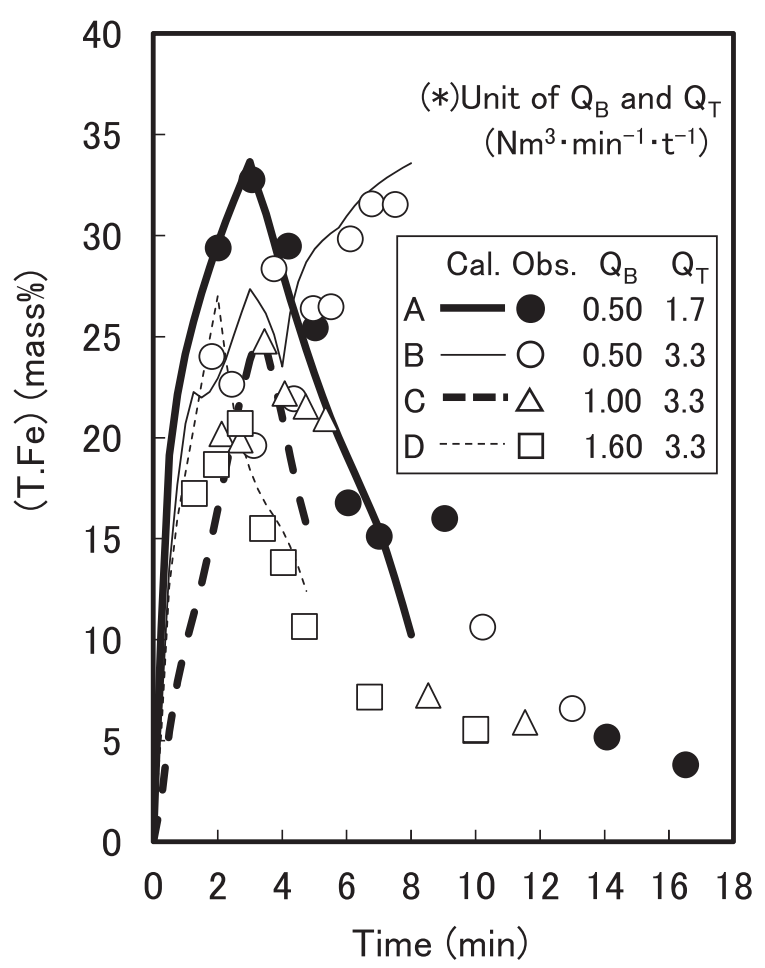

Fig. 7. Time variation in (T.Fe).

blowing and scattering loss of lime powder supplied from the top lance were negligible small because both values are in good agreement.

Time variation in (T.Fe) is shown in Fig. 7. (T.Fe) in Heat-A was more than 30 mass $\%$ at the initial stage and decreased with time but remained over 15 mass $\%$ throughout the blowing time. (T.Fe) also reached over 30 mass $\%$ at 7 min in Heat-B where $\mathrm{Q}_{\mathrm{T}}$ was twice as much as in Heat-A. (T.Fe) decreased with increasing $\mathrm{Q}_{\mathrm{B}}$ under the same condition for $\mathrm{Q}_{\mathrm{T}}$ of $3.3 \mathrm{Nm}^{3} \cdot \mathrm{min}^{-1} \cdot \mathrm{t}^{-1}$. In particular, (T.Fe) decreased to less than 10 mass $\%$ in the final stage of the blowing time in Heat-D.

\section{Discussion}

\subsection{Estimation of Experimental Results with "Coupled Reaction Model"}

The experimental results were estimated using "Coupled 


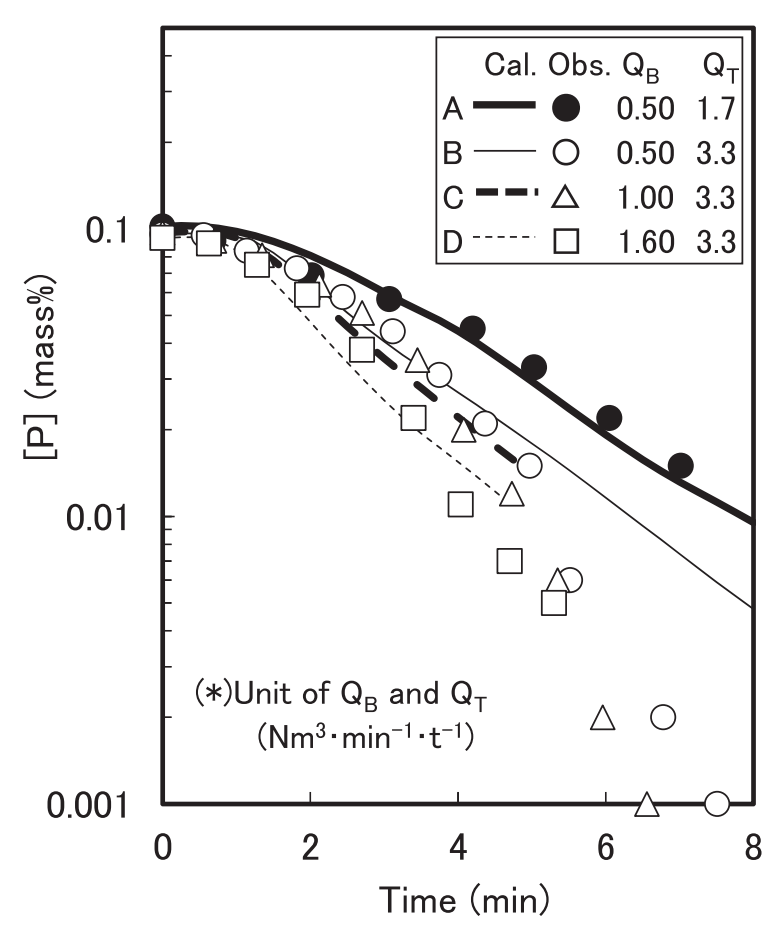

Fig. 8. Time variation in phosphorus content of hot iron.

Reaction Model" proposed by Kitamura et al. ${ }^{11)}$ It is assumed, in the present model, that (1) lime powder dissolves quickly into top slag and (2) dephosphorization reaction occurs at the interface between hot iron and top slag. The former assumption is confirmed as shown in Fig. 5. The latter assumption have to be confirmed by comparing experimental results with calculated ones because the effect of powder is not considered. Under the condition of low phosphorus content at the final stage, from $8 \mathrm{~min}$ at Heat$\mathrm{A}$ and $-\mathrm{B}$ and $4.8 \mathrm{~min}$ at Heat-C and $-\mathrm{D}$, coupled reaction model could not explain the experimental results because the model was based on the dephosphorization reaction between slag and hot iron and did not take into consideration the reaction by $\mathrm{FeO}-\mathrm{CaO}$ melt at hot spot.

The calculated temperature, $[\mathrm{C}],[\mathrm{P}],(\mathrm{CaO}) /\left(\mathrm{SiO}_{2}\right)$ and (T.Fe) during treatment are shown in Figs. 1 to 5 and they show good agreement with experimental result. However, the behavior in the lower phosphorus content is not necessarily clear in Fig. 4. Therefore, single logarithmic plot of $[\mathrm{P}]$ is drawn in Fig. 8. It shows that the calculated $[\mathrm{P}]$ is in good agreement with the observed ones but is higher at $[\mathrm{P}]$ below 0.02 mass \%. It suggests that it is necessary to take into consideration reaction at hot spot where top-blown particles contact with hot iron as well as reaction between top slag and hot iron.

Figure 8 shows that the logarithm of $[\mathrm{P}]$ decreases proportionally with time. Rate constant, $\mathrm{K}\left(\mathrm{min}^{-1}\right)$, of dephosphorization at $[\mathrm{P}]$ below 0.02 mass $\%$ was calculated based on Fig. 8 and plotted against stirring power, ${ }^{12)}$ in Fig. 9. Rate constant can be obtained from Eq. (1) where $[\mathrm{P}]_{\mathrm{e}}$ represents equilibrium content of phosphorus in hot iron. In the calculation, $[\mathrm{P}]_{\mathrm{e}}$ is set to be zero.

$$
-\frac{d[P]}{d t}=K\left([P]-[P]_{e}\right)
$$

Rate constant, $\mathrm{K}$, has maximum value at stirring power $\varepsilon$ of $2800 \mathrm{~W} \cdot \mathrm{kg}^{-1}$ as shown in Fig. 9. It is suggested that too

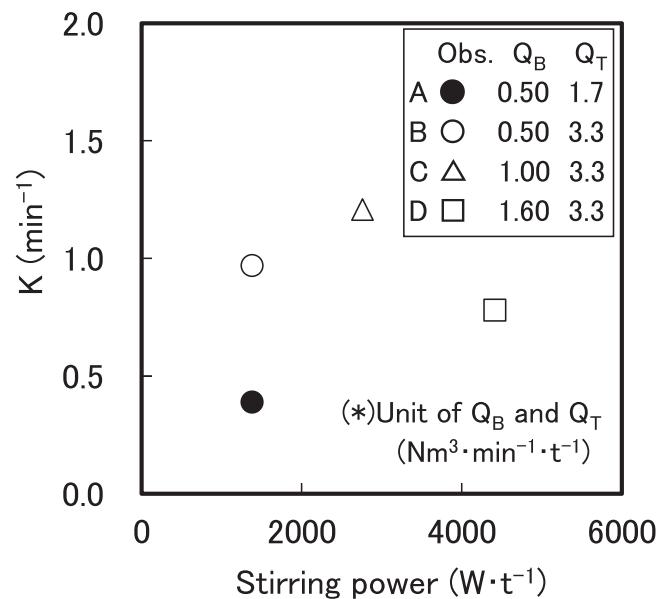

Fig. 9. Relation between rate constant of dephosphorization and stirring power.

much stirring power decreases rate constant of dephosphorization. $\mathrm{K}$ in Heat-B increased by a factor of 2.5 compared with that in Heat-A, where the flow rate of the top blowing oxygen gas was half as that in Heat-B. However, $\varepsilon$ of 1300 $\mathrm{W} / \mathrm{t}$ in both experiments was below $4000 \mathrm{~W} \cdot \mathrm{kg}^{-1}$, a critical condition, in which $\mathrm{K}$ is independent of the oxygen flow rate according to Mukawa et al. ${ }^{13)}$ The difference between them might be explained with the influence of lime powder on dephosphorization at hot spot because Mukawa et al. confirmed the critical condition without powder top blowing. This behavior will be discussed later.

\subsection{Equilibrium Achievement in Dephosphorization}

The apparent equilibrium achievement degree was discussed using Eq. (2) on phosphorus distribution, $\mathrm{L}_{\mathrm{P}, \text { cal., }}$ proposed by Ogawa et al. ${ }^{14)}(\%)$ or [\%] represents mass $\%$ and $\mathrm{T}$ represents absolute temperature $(\mathrm{K})$ in Eq. (2).

$$
\begin{aligned}
& L_{P, \text { cal. }}=\log \frac{(\% \mathrm{P})}{[\% \mathrm{P}]} \\
& =2.5 \log (\% \mathrm{T.Fe})+0.0715\{(\% \mathrm{CaO})+0.25(\% \mathrm{MgO})\} \\
& +\frac{7710.2}{T}-8.55\left(\frac{105.1}{T}+0.0723\right)[\% \mathrm{C}]
\end{aligned}
$$

Time variation in observed phosphorus distribution, $\mathrm{L}_{\mathrm{P} \text {,obs. }}$, showed much higher than $\mathrm{L}_{\mathrm{P} \text {,cal. }}$ particularly in the final stage of blowing, as shown in Fig. 10. It is suggested that dephosphorization reaction could not be explained using only equilibrium relationship between top slag and hot iron.

\subsection{Estimation of the Content of $\mathrm{FeO}-\mathrm{CaO}$ Melt Formed at the Hot Spot}

As mentioned above, the behavior of dephosphorization at the final stage of blowing might result from the condition that the dephosphorization reaction at hot spot was not negligible. In the present section, the content of $\mathrm{FeO}-\mathrm{CaO}$ melt at hot spot in the final stage of blowing is calculated on a basis of the following assumptions that (1) top blowing oxygen except to be consumed for decarburization forms $\mathrm{FeO}$ and (2) top blowing lime powder forms $\mathrm{FeO}-\mathrm{CaO}$ melt. As a result, $\mathrm{FeO}$ content of the melt can be calculated as $64,80,79$ and $58 \%$ for Heat-A, Heat-B, Heat-C and 


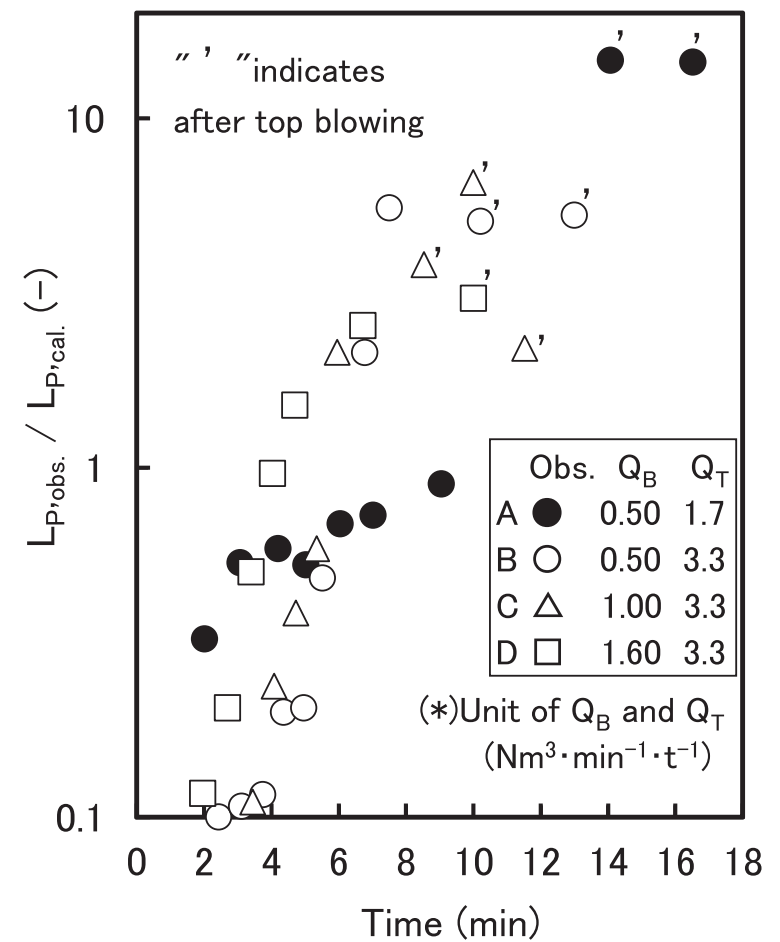

Fig. 10. Time variation in apparent equilibrium achievement degree.

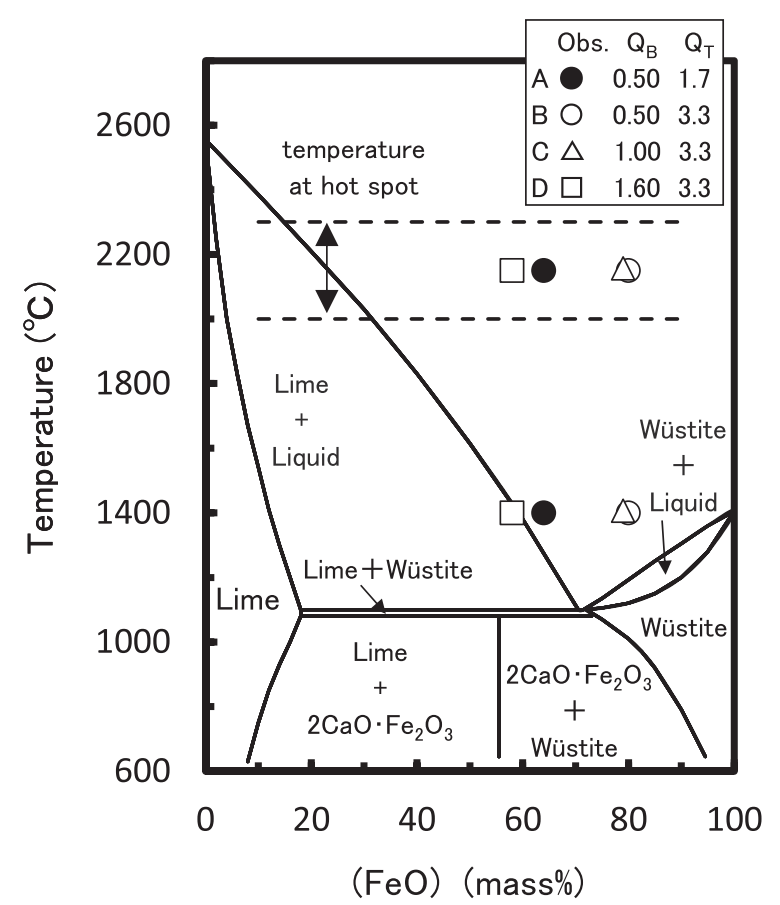

Fig. 11. Calculated content of $(\mathrm{FeO})$ at hot spot.

Heat-D, respectively. The lower content of FeO for Heat-D results from higher decarburization rate due to higher stirring power. $\mathrm{FeO}$ contents of the melts are plotted in Fig. 11 based on $\mathrm{CaO}-\mathrm{FeO}$ binary phase diagram, ${ }^{15}$ ) considering the temperature of hot spot ranging from 2273 to $2573 \mathrm{~K}$ (from 2000 to $2300^{\circ} \mathrm{C}$ ) ${ }^{16)}$ and of hot iron around $1673 \mathrm{~K}$ $\left(1400^{\circ} \mathrm{C}\right)$. All of the melts are thought to be liquid at hot spot. However, the liquidus of the melt in Heat-D is relatively high compared with Heat-A, Heat-B, and Heat-C. The melt with small difference of temperature between hot spot and liquidus could easily solidify a little away from hot spot.

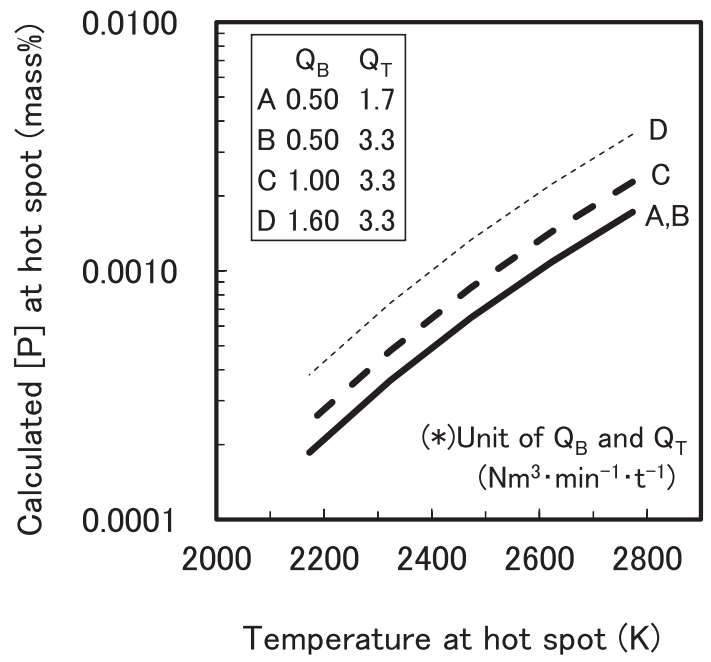

Fig. 12. Relation between calculated $[\mathrm{P}]$ and temperature at hot spot.

The lower rate constant, K, in Heat-D as shown in Fig. 9 might be attributed to this because the solidification of the melt could work against dephosphorization reaction.

\subsection{Dephosphorization Behavior at Hot Spot}

The dephosphorization behavior in the range of ultralow $[\mathrm{P}]$ at hot spot is thermodynamically discussed according to the procedure shown below:

(1) Determination of the content of $\mathrm{FeO}-\mathrm{CaO}-\mathrm{P}_{2} \mathrm{O}_{5}$ melt at hot spot using the calculated results in the previous section and generation rate of $\mathrm{P}_{2} \mathrm{O}_{5}$ converted from change in [P].

(2) Estimation of $[\mathrm{P}]$ at hot spot on a basis of Healy's equation, ${ }^{17)}$ Eq. (3) for the temperature at hot spot ranging from 2273 to $2573 \mathrm{~K}$ (from 2000 to $2300^{\circ} \mathrm{C}$ ). (\%) or [\%] in Eq. (3) represents mass \% and (\%.TFe) is converted from $(\% \mathrm{FeO})$ in the procedure (1) mentioned above.

$$
\log \left\{\frac{(\% P)}{[\% P] \cdot(\% T . F e)^{2.5}}\right\}=0.08(\% \mathrm{CaO})+\frac{22350}{T}-16 \ldots
$$

The calculated contents of phosphorus plotted against the temperature in Fig. 12 are lower than the observed [P] at the averaged temperature of $2423 \mathrm{~K}\left(2150^{\circ} \mathrm{C}\right)$. Much higher phosphorus distribution than equilibrium relationship between slag and hot iron was observed in the final stage of blowing. It is suggested that high oxygen potential of $\mathrm{FeO}-\mathrm{CaO}$ melt could compensate with negative effect of high temperature at hot spot.

\subsection{Relation between (T.Fe) and the Top and Bottom Blowing Conditions}

Control of (T.Fe) during top blowing is necessary in the commercial operation due to its strong influence on slopping phenomena. It is difficult to control (T.Fe) because it is affected by experimental conditions such as temperature, $(\mathrm{CaO}) /\left(\mathrm{SiO}_{2}\right)$ and top and bottom blowing conditions. Among these, $(\mathrm{CaO}) /\left(\mathrm{SiO}_{2}\right)$ had a relatively small effect on (T.Fe) under the condition of $(\mathrm{CaO}) /\left(\mathrm{SiO}_{2}\right)$ ranging from 1.8 to 3.0 and temperature of $1580-1630 \mathrm{~K}$ as shown in Fig. 13.

(T.Fe) in the range depended strongly on the top and 


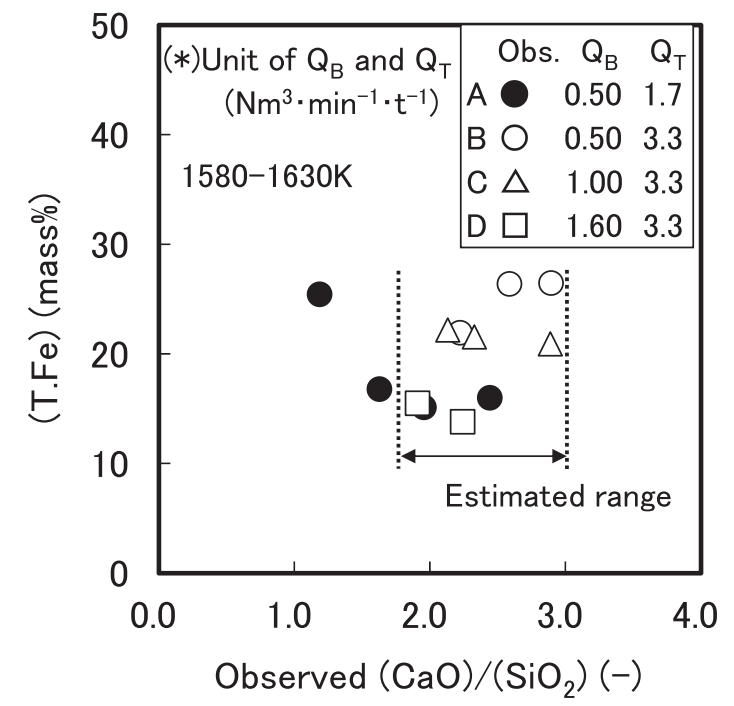

Fig. 13. Relation between (T.Fe) and slag basicity, $(\mathrm{CaO}) /\left(\mathrm{SiO}_{2}\right)$.

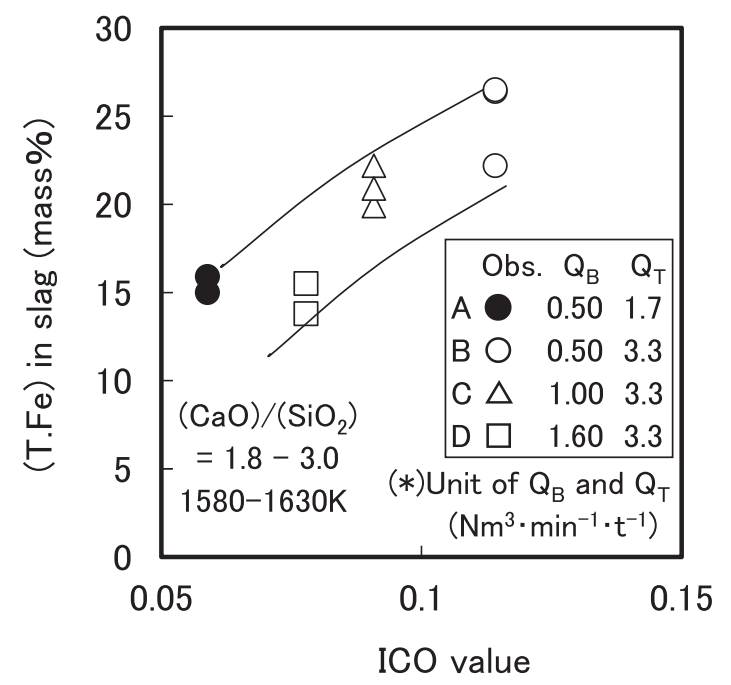

Fig. 14. Relation between (T.Fe) and ICO value.

bottom blowing conditions and the effect of the blowing condition on (T.Fe) was estimated using ICO value, index of metallurgical characteristics in BOF, proposed by Higuchi et $a l .{ }^{18)}$ ICO value can be calculated using Eq. (4).

$$
I C O=4.2 \times 10^{3} \cdot\left(\frac{Q}{W}\right) \cdot\left(\frac{L}{L o}\right)^{-0.4} \cdot \dot{\varepsilon}^{-0.33} \cdot[\% C]^{-1}
$$

where Q represents the flow rate of the top blowing oxygen $\left(\mathrm{Nm}^{3} \cdot \mathrm{s}^{-1}\right)$, W represents the weight of metal $(\mathrm{kg}), \mathrm{L}$ represents the cavity depth formed on the metal surface by top blowing $(\mathrm{mm}),{ }^{19)}$ Lo represents the bath depth $(\mathrm{mm}), \varepsilon$ represents the stirring power per weight $\left(\mathrm{W} \cdot \mathrm{kg}^{-1}\right),{ }^{12)}$ and
[C] represents the carbon content of hot iron (mass\%).

Relation between (T.Fe) and ICO value shown in Fig. 14 indicates that (T.Fe) increased with increasing ICO within some variation. It suggests that (T.Fe) can be controlled using the top and bottom blowing conditions.

\section{Conclusions}

Experiments on the lime powder top blowing method for the dephosphorization of hot iron were conducted using a $2 \mathrm{t}$ test top and bottom blown converter. Results obtained are as follows:

(1) By simultaneously adopting lime powder top blowing and ladle slag addition, phosphorus content of hot iron decreased to 0.009 and 0.001 mass $\%$ under the condition of $(\mathrm{CaO}) /\left(\mathrm{SiO}_{2}\right)=3$.

(2) Rate constant, K, of dephosphorization reaction below $[\mathrm{P}]=0.02$ mass $\%$ increased with increasing bottom gas flow rate, but $\mathrm{K}$ decreased under the condition of too much bottom gas flow rate.

(3) Phosphorus distribution in the final stage of blowing was much higher than predicted values on a basis of thermodynamic relation between top slag and hot iron.

(4) It is suggested that the $\mathrm{FeO}-\mathrm{CaO}$ melt formed at hot spot is capable of decreasing the phosphorus content of hot iron to the ultralow range even at high temperature at hot spot.

\section{REFERENCES}

1) T. Ikeda and T. Matsuo: Trans. Iron Steel Inst. Jpn., 22 (1982), 495.

2) Y. Kawai, H. Nakamura, K. Kawakami, T. Toyoda, A. Ishizaka and T. Ebisawa: Tetsu-to-Hagané, 69 (1983), 1755.

3) K. Iwasaki, N. Sano and Y. Matsushita: Tetsu-to-Hagané, 67 (1981), 536.

4) K. Ito and N. Sano: Tetsu-to-Hagané, 69 (1983), 1747.

5) Y. Ogawa, M. Yano, M. Matsuo and Y. Demoto: CAMP-ISIJ, 6 (1993), 1074.

6) S. Ban-ya, M. Hino, R. Nagabayashi and O. Terayama: Tetsu-toHagané, 75 (1989), 66.

7) M. Miyata, S. Fukagawa, K. Shinme and H. Li: CAMP-ISIJ, 8 (1995), 101.

8) M. Miyata, S. Fukagawa and T. Matsuo: CAMP-ISIJ, 16 (2003), 115.

9) Y. Umeda, T. Aoki, T. Matsuo, S. Masuda, M. Taga and H. Nakajima: Tetsu-to-Hagané, 68 (1982), S202.

10) H. Nashiwa, S. Yamaguchi, M. Sato, K. Ieda, M. Ishikawa and Y. Ohkita: Tetsu-to-Hagané, 68 (1982), S203.

11) S. Kitamura, K. Ito, F. Pahlevani and M. Mori: Tetsu-to-Hagané, 100 (2014), 491.

12) M. Sano and K. Mori: Tetsu-to-Hagané, 68 (1982), 2451.

13) S. Mukawa and Y. Mizukami: Tetsu-to-Hagané, 80 (1994), 207.

14) Y. Ogawa, M. Yano, S. Kitamura and H. Hirata: Tetsu-to-Hagané, 87 (2001), 21.

15) R. E. Johnson and A. Muan: J. Am. Ceram. Soc., 48 (1965), 360.

16) K. Kawakami: Tetsu-to-Hagané, 74 (1988), 831.

17) G. W. Healy: J. Iron Steel Inst., 208 (1970), 664.

18) Y. Higuchi and Y. Tago: Tetsu-to-Hagané, 86 (2000), 654.

19) Y. Araki: Doctoral thesis, Engineering Department, Kyoto University, (1976). 